\title{
STATE-OF-THE-ART OF RESEARCH ON SEISMIC POUNDING BETWEEN BUILDINGS WITH ALIGNED SLABS
}

\author{
Alireza KHARAZIAN ${ }^{1}$ and Francisco LÓPEZ-ALMANSA ${ }^{2}$
}

\begin{abstract}
Collision between adjoining buildings with aligned slabs is relevant, since the huge impact forces significantly modify the buildings dynamic behavior. The separation required by the regulations avoids pounding; however, even in recent buildings, impact can occur due to not fulfillment of codes and seismicity underestimation. Given the importance of this issue, a significant research effort has been undertaken worldwide, and a considerable number of papers are available. The complexity of this field and this abundance of information might require a review task. This paper presents a summary of the theoretical developments, discusses the most common simulation software, provides an overview of the previous research, offers recommendations to researchers, and identifies research needs.
\end{abstract}

Keywords: Seismic pounding, colliding adjoining buildings, numerical simulation.

\section{INTRODUCTION}

During strong seismic events, impact between contiguous buildings is relevant, since the huge collision forces significantly modify their dynamic behavior. In some occasions, the effect of impact might be beneficial, mainly in terms of interstory drift; conversely, in many other situations, pounding is detrimental, particularly in terms of absolute acceleration. Collapse and nonstructural damage of buildings due to seismic pounding have been reported. Collision can be avoided by adequately separating the involved buildings, and this gap is routinely required by the design codes; however, impact can anyway occur because of several reasons: sometimes code prescriptions are not fulfilled, some past codes did not oblige any such separation, and the seismicity can be underestimated. Therefore, seismic pounding of buildings is something to be taken into consideration.

Collision between adjoining buildings can be classified into slab-to-slab and slab-to-column (or slabto-wall) impact; such cases correspond to aligned and unaligned slabs, respectively. The second type is by far more dangerous, since the impact of a rigid and massive slab on a column (or even on a wall) is most likely to lead to collapse. On the other hand, the first type is not free of danger and is considerably more frequent, since adjoining buildings with unaligned slabs are regularly avoided. Moreover, the numerical simulation of slab-to-slab impact is challenging, involving stress traveling waves, high-frequency behavior and significant local effects. This study focuses on seismic pounding between adjoining buildings with aligned slabs.

Given the importance and complexity of this issue, a considerable number of papers, books and reports have been published so far. This review paper has the following general objectives: (i) presenting a summary of the most relevant theoretical developments, (ii) discussing the most common simulation software, (iii) providing a critical global overview of the previous research in this vast field, (iv) offering recommendations to new researchers, and (v) identifying new research needs. This paper is organized according to these objectives.

\section{MODELLING OF SEISMIC POUNDING}

\subsection{General considerations}

\footnotetext{
${ }^{1}$ PhD Candidate, Technical University of Catalonia, Barcelona, alireza.kharazian@upc.edu

${ }^{2}$ Professor, Technical University of Catalonia, Barcelona, francesc.lopez-almansa@upc.edu
} 
As outlined in the Introduction, collision between two building slabs is a complex phenomenon. The most natural approach is the classical impact theory, being based on the solution of the 3-D continuum partial derivative equations of motion (distributed-parameter models). In some geometrically simple cases, such equations can be solved exactly; the ensuing closed-form solutions can be useful when the required simplifying assumptions are feasible. Going to numerical formulations, sophisticated continuum mechanics-based models are available, but they are extremely time-consuming and are therefore unsuitable for extensive use in actual structures. Therefore, the use of concentrated models has been suggested; they are intended to be used with infinitely rigid slabs models. The simplest one is the stereomechanical [Goldsmith 1960]; the colliding slabs are represented by concentrated masses connected by a spring with infinitive stiffness and the plasticity is modeled by a restitution factor. The linear spring model is similar, although incorporates also a linear spring with finite stiffness. These two models can be considered as oversimplified; among the useful approaches, the simplest one is the Kelvin-Voigt model, also known as linear viscoelastic. It is the most spread formulation and is widely described herein, together with the modified Kelvin-Voigt model. Other more complex models (Nonlinear viscoelastic, Hertzdamp) are also analyzed. The Sears model is discussed as well; it combines distributed and lumped elements.

\subsection{Classical impact theory}

\subsubsection{Axial vibration of an elastic bar}

This subsection presents an analytical study of damped axial vibrations of elastic uniform (constantsection) straight bars; deeper analyses can be found in [Goldsmith 1960; Graff 1975; Stronge 2004]. Only waves progressing in a single direction are considered. Figure 1 displays a vibrating bar (Figure 1.a) and a differential segment of it (Figure 1.b). In Figure 1.a, $L$ is the bar length, $E$ is the equivalent elastic deformation modulus, and $A$ is the cross-section area; in Figure 1.b, $N$ is the internal axial force (tension positive) and $x$ is the longitudinal coordinate.

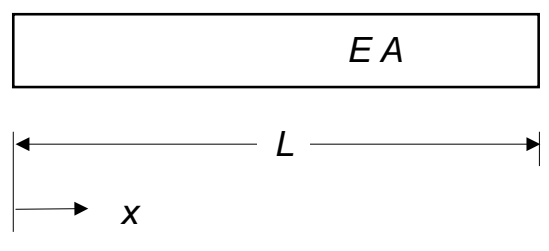

(a) Vibrating bar

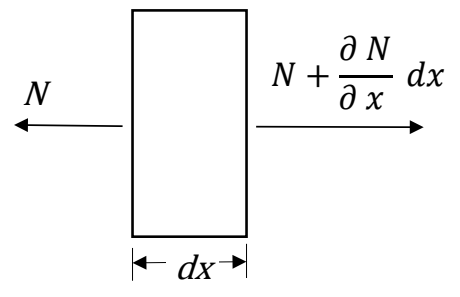

(b) Differential segment

Figure 1. Axial vibration of an elastic bar

The damped equation of motion in $x$ direction of the slice displayed in Figure 1.b is given by the following partial derivatives differential relation

$$
\frac{E}{\bar{\rho}} \frac{\partial^{2} u}{\partial x^{2}}=\frac{\partial^{2} u}{\partial t^{2}}+\frac{c}{A \bar{\rho} d x} \frac{\partial u}{\partial t}
$$

In equation (1), $t$ is time, $u$ is the axial displacement, $c$ is the damping coefficient, and $\bar{\rho}$ is the equivalent density, given by $\bar{\rho}=\rho+\frac{\bar{m}_{0}}{A}$, where $\rho$ is the density and $\bar{m}_{0}$ is the part of external mass per unit length that is mobilized during the axial vibrations. In rather slender rods, plane stress conditions can be assumed. Conversely, in wide building slabs or bridge decks, the transverse stress waves cannot alleviate instantaneously the transverse compression; hence, the concrete behaves basically as confined, e.g. in plane strain conditions.

Modal analysis can be performed by separation of variables, e.g. searching solutions of equation (1) given by the product of two functions depending only on $x$ and on $t: u(x, t)=\phi(x) q(t)$. In that case, $u$ " 
$=\phi ” q, \dot{u}=\phi \dot{q}$ and $\ddot{u}=\phi \ddot{q}$, then $\frac{E}{\bar{\rho}} \frac{\phi^{\prime \prime}}{\phi}=\frac{\ddot{q}}{q}+\frac{c}{A \bar{\rho} d x} \frac{\dot{q}}{q}$. Since the first/second terms depend only on $x / t$, it is obvious that both are constant, namely $-\omega^{2}$. Therefore, the partial derivatives equation (1) can be split into two ordinary linear differential space-dependent and time-dependent equations:

$$
\frac{E}{\bar{\rho}} \phi^{\prime \prime}+\omega^{2} \phi=0 \quad \ddot{q}+2 \omega \zeta \dot{q}+\omega^{2} q=0
$$

In the right equation (2), the damping ratio $\zeta$ is given by $\zeta=\frac{c}{2 \omega A \bar{\rho} d x}$. The general solutions of equations (2) are respectively given by

$$
\phi(x)=A \cos \lambda x+B \sin \lambda x \quad q(t)=e^{-\omega \zeta t}\left(C \cos \omega \sqrt{1-\zeta^{2}} t+D \sin \omega \sqrt{1-\zeta^{2}} t\right)
$$

In equations (3), $\lambda=\omega\left(\frac{\bar{\rho}}{E}\right)^{1 / 2}$. The undamped natural frequencies $(\omega)$ and the eigenmodes (given by $\phi)$ depend on the boundary and initial conditions. Noticeably, although this type of vibration is the most natural that the bar can experience, can be generated only starting from initial conditions that be compatible with its configuration. For instance, the impact between two colliding bars impose completely different initial conditions, since, at the collision instant, the velocity of all points of both bodies is equal to the one before impact, but the velocity of the colliding ends is different. This generates a discontinuity in the velocities that is not present in the modal conditions. Next subsection discusses more deeply this issue.

\subsubsection{Elastic impact analysis}

This subsection describes the internal behavior of colliding elastic bodies. The impact is assumed to be elastic; e.g. there is no energy loss. The analysis of the impact starts from the general solution of the equation of motion (1) by the d'Alembert method. That approach considers the change of variables given by $x-c t=\xi$ and $x+c t=\psi$, where the constant $c$ is given by $c=\left(\frac{E}{\bar{\rho}}\right)^{1 / 2}$ and represents the traveling waves (relative) velocity. Equation (1) becomes $\frac{\partial^{2} u}{\partial \xi \partial \psi}=0$ [Kharazian 2017]; its general solution is given by

$$
u(x, t)=f(\xi)+g(\psi)=f(x-c t)+g(x+c t)
$$

In equation (4), $f$ and $g$ are any pair of functions fulfilling the initial and boundary conditions. For such functions, $\quad f\left(x+\delta, t+\frac{\delta}{c}\right)=f(x+\delta-c t-\delta)=f(x-c t)=f(x, t)$ and $g\left(x-\delta, t+\frac{\delta}{c}\right)=$ $g(x-\delta+c t+\delta)=g(x+c t)=g(x, t)$, where $\delta$ is a displacement; therefore, $f$ and $g$ represent constant velocity waves traveling to the right and to the left, respectively. Their shape depends on the initial and boundary conditions.

Figure 2 describes the collinear impact between two elastic bodies with different length and axial stiffness, although with the same equivalent mass density $\bar{\rho}$. In Figure 2, $v_{1}$ and $v_{2}, L_{1}$ and $L_{2}$, and $E A_{1}$ and $E A_{2}$, are the traveling velocity, length and axial stiffness of each colliding body, respectively. The mass of the rods is $m_{1}=\bar{\rho} A_{1} L_{1}$ and $m_{2}=\bar{\rho} A_{2} L_{2}$, respectively. It is assumed that $L_{1} \leq L_{2}$ but $2 L_{1}$ $\geq L_{2}$. Using a Lagrangian formulation, $x$ is the coordinate with respect to the contact interface (right/left end sections of left/right body, respectively). $F$ is the contact force in the interface between both bodies. A thorough description of Figure 2.a through Figure 2.h is given next.

- Figure 2.a displays the colliding bodies prior impact.

- Figure 2.b and Figure 2.c represent the beginning and the initial instants of impact, respectively. At impact, the velocity of the interface shifts instantaneously from $v_{1}$ to $v_{\mathrm{c}}$ (joint velocity, during 
the impact duration, of the interface between both bodies and the adjoining strained segments); this change generates a discontinuity. After contact, two stress (and strain) waves propagate outwards to the interface with constant velocity $c$.

- Figure 2.d through Figure 2.f depict the peak and the second part of the impact. Once the wave reaches the free end of the bar, it reflects, and the end segment is being progressively unstrained. After-impact velocities $v^{\prime}{ }_{1}$ and $v_{2}{ }_{2}$ refer to the unstrained segments of the left and right bodies, respectively.

- Figure 2.g shows the condition of the bodies at the end of the impact, e.g. when the returning wave of the left body has reached the interface and all its length is unstrained. The impact duration is equal to the axial vibration period of the shortest rod [Malhotra 1998]; noticeably, this interval is extremely short.

- Figure 2.h refers to any further instant, when the left body travels unstrained with constant velocity while the right has some longitudinal vibrations.

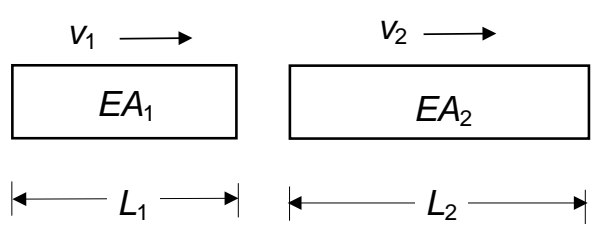

(a) Before the impact $(t<0)$

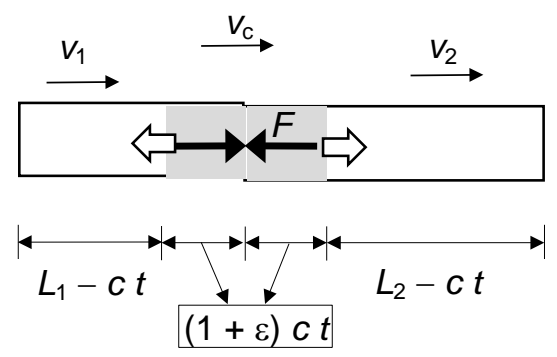

(c) First half of impact $\left(0 \leq t \leq L_{1} / c\right)$

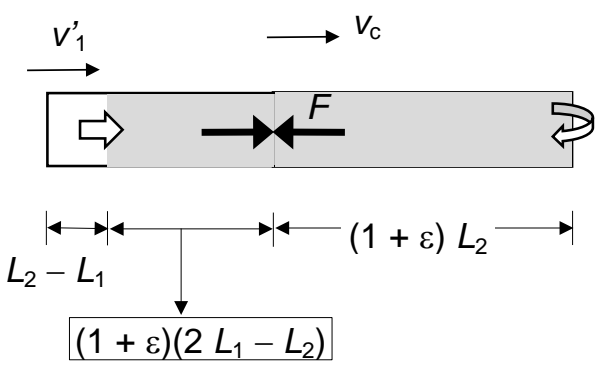

(e) Fully strained long body $\left(t=L_{2} / c\right)$
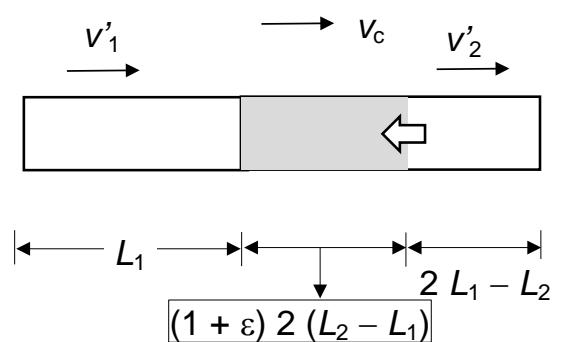

(g) End of impact $\left(t=2 L_{1} / c\right)$

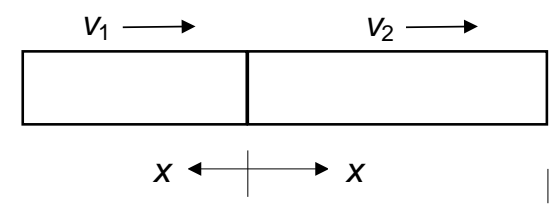

(b) Onset of impact $(t=0)$

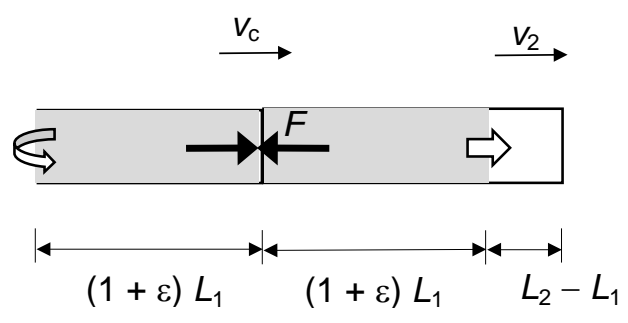

(d) Peak of impact $\left(t=L_{1} / c\right)$

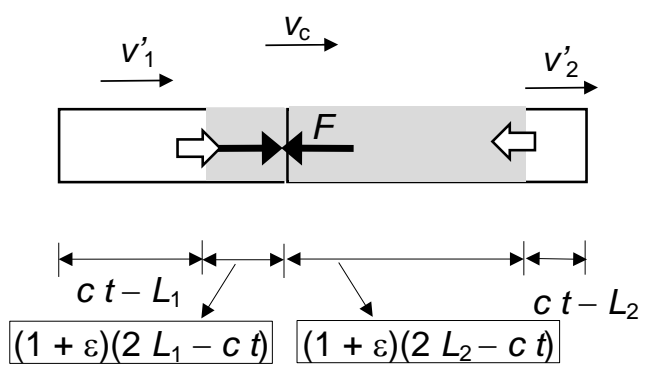

(f) Second half of impact $\left(L_{2} / c \leq t \leq 2 L_{1} / c\right)$

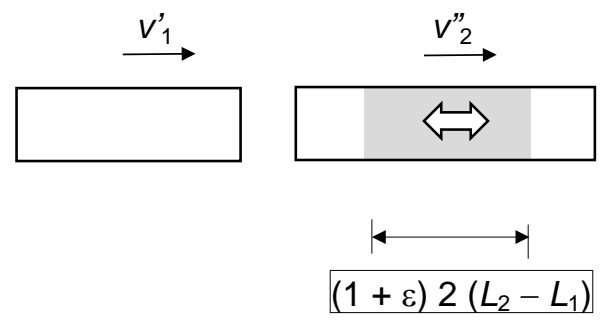

(h) After the end of impact $\left(t>2 L_{1} / c\right)$

Figure 2. Two colliding elastic bodies 
The momentum conservation principle shows [Kharazian 2017] that $v_{c}=\frac{m_{1} L_{2} v_{1}+m_{2} L_{1} v_{2}}{m_{1} L_{2}+m_{2} L_{1}}$; analogously, it is obtained that $v_{1}^{\prime}=2 v_{\mathrm{c}}-v_{1}$ and $v^{\prime}{ }_{2}=2 v_{\mathrm{c}}-v_{2}$. The impact force $F$ can be obtained by equaling the difference of momentum between Figure 2.b and Figure 2.d and the impulse; after some algebra [Kharazian 2017] it is concluded that $F=\frac{c m_{1} m_{2}\left(v_{2}-v_{1}\right)}{m_{1} L_{2}+m_{2} L_{1}}$. The momentum conservation principle shows that, after the impact, the weighted average velocity $v_{2}{ }_{2}$ in the right body is constant, being given by $v_{2}^{\prime \prime}=v_{2}+\frac{2 m_{1} L_{1}\left(v_{1}-v_{2}\right)}{m_{1} L_{2}+m_{2} L_{1}}$.

The restitution factor $r$ is commonly defined as the ratio between the post-impact and initial relative velocities between the colliding bodies; given that the right slab has some residual vibration, it can be defined in any of these forms:

$$
r=\frac{v_{2}^{\prime}-v_{1}^{\prime}}{v_{1}-v_{2}} \quad r^{\prime}=\frac{v_{2}{ }_{2}-v_{1}^{\prime}}{v_{1}-v_{2}}
$$

\subsection{Kelvin-Voigt model (Linear viscoelastic model)}

\subsubsection{Normal Kelvin-Voigt model}

The Kelvin-Voigt model is a zero-length element consisting in the parallel combination of a linear spring and a linear dash-pot, as displayed in Figure 3.a; $d$ is the gap size, and $k$ and $c$ are the stiffness and damping coefficients, respectively. Figure 3.b displays the distribution of Kelvin-Voigt models in the adjoining pounding buildings. Figure 3.c represents a strained state of Kelvin-Voigt model; noticeably, if $x_{1}-x_{2}>d$, there is virtual penetration between both slabs.

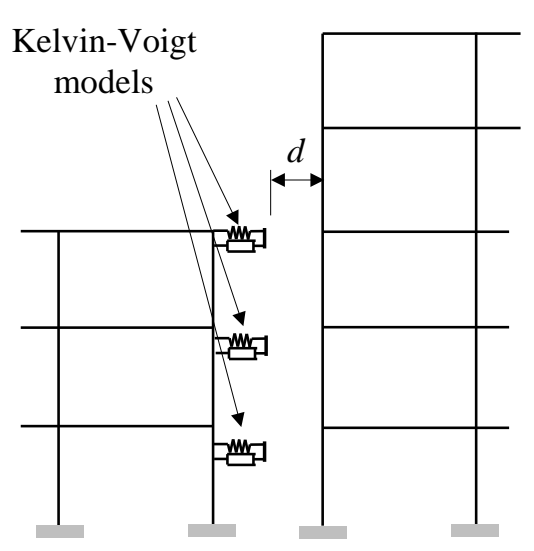

(b) Distribution of Kelvin-Voigt models

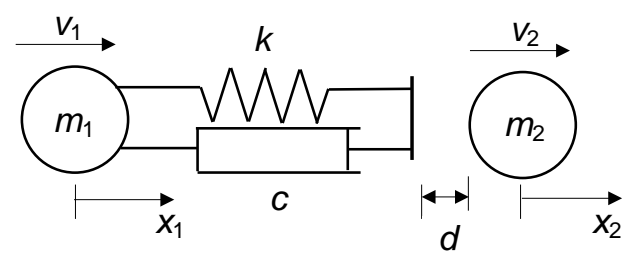

(a) Unstrained Kelvin-Voigt model

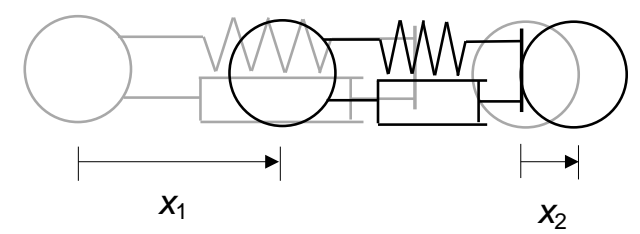

(c) Strained Kelvin-Voigt model during impact

Figure 3. Lumped Kelvin-Voigt models for simulation of pounding between adjoining buildings with aligned slabs

The constitutive law of the Kelvin-Voigt model is given by

$$
F=k\left(x_{1}-x_{2}-d\right)+c\left(\dot{x}_{1}-\dot{x}_{2}\right) \text { if } x_{1}-x_{2} \geq d \quad F=0 \text { if } x_{1}-x_{2}<d
$$

In past studies the Kelvin-Voigt model stiffness has shown little influence on the displacement response and has proven strongly dependent on many randomly varying parameters. Thus, only loose criteria for selecting it have been provided: studies [Anagnostopoulos 1988; Khatiwada, Chouw 2014] suggest using significantly higher values than the lateral stiffness of the colliding buildings, [Anagnostopoulos, Spiliopoulos 1992] recommends that the local periods of the mass-impact springs keep below the lowest translational periods of the pounding buildings, [Maison, Kasai 1992] proposes considering the axial stiffness of the floor slabs, [Watanabe, Kawashima 2004] refers also to the axial 
stiffness of the slabs but check also higher and lower values, and finally, [Liu et al. 2014] proposes an expression depending on Hertz stiffness for spherical contact, and on maximum penetration. All the studies recommend that the stiffness of the Kelvin-Voigt model be considerably higher than the lateral stiffness of the buildings.

In the distributed parameter model formulation (subsection 2.2) the impact force is constant during the collision duration; conversely, using the Kelvin-Voigt model, such force is given by equation (6). Therefore, it is not possible to obtain any exact equivalence between both formulations [Cole et al. 2009; Cole et al. 2011].

Conversely to stiffness, damping is universally recognized as a more relevant parameter, significantly affecting virtually all the relevant response parameters; therefore, more attention has been paid to this issue. The physical meaning of the restitution factor is more obvious than that of the damping parameter; therefore, [Anagnostopoulos 2004] derives a closed-form expression of damping in terms of $r$. In that work, the influence of the structures of the colliding buildings and of the seismic excitation during impact are neglected. These assumptions are based on the higher stiffness and damping of Kelvin-Voigt model compared to those of the buildings, and on the input randomness, given the extremely short impact duration. After these simplifications, Anagnostopoulos performed a modal analysis of the ensuing two-degree of freedom system (Figure 3.a) and derived closed-form solutions of the uncoupled scalar equations of motion in modal coordinates. The first mode involves only rigid-body motion and has no stiffness and no damping; the natural frequency $(\omega)$ and the damping ratio $(\zeta)$ of the second mode are given by

$$
\omega=\sqrt{k \frac{m_{1}+m_{2}}{m_{1} m_{2}}} \quad \zeta=\frac{c}{2} \sqrt{\frac{m_{1}+m_{2}}{k m_{1} m_{2}}}
$$

The aforementioned closed-form solution of the second mode is determined after their parameters in equation (7). Then, the impact duration $(t)$ is obtained, and later the restitution factor is calculated from equation (5):

$$
t=\frac{\pi}{\omega\left(1-\zeta^{2}\right)^{1 / 2}} \quad \zeta=\frac{-\ln r}{\sqrt{\pi^{2}+\ln ^{2} r}}
$$

The left equation (8) shows that the impact duration is extremely short (as mentioned in subsection 2.2.2), given that $k$ is rather high. The right equation (8) shows that, if $r=0, \zeta=1$ and if $r=1, \zeta=0$.

To summarize, this approach consists in estimating initially the restitution factor $r$, obtaining damping ratio $\zeta$ with equation (8) and then the damping parameter $c$ with the second equation (7). The accuracy of this strategy can be evaluated by obtaining the actual value of $r$ and comparing with the target one. This very simple and widely used model has been compared with more complicated solutions and has proven to provide comparable or even better accuracy [Mavronicola et al. 2015; Mavronicola et al. 2016]. The work [Kharazian 2017] proposes an alternative formulation leading to a different estimation of damping parameter; better accuracy is obtained.

In the seismic pounding between two RC building frames with 5 and 3 stories, Figure 4 displays time histories of the third floor impact force [Kharazian 2017]. Figure 4.a represents the full shaking duration, while Figure 4.b contains a zoom (time window) of the strongest collision. These results have been obtained with SeismoStruct [SeismoSoft 2016]; the impact is described with the normal Kelvin-Voigt model. 


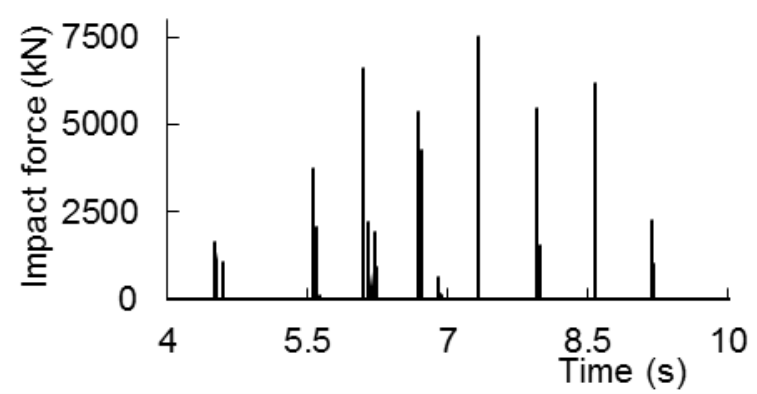

(a) Full duration

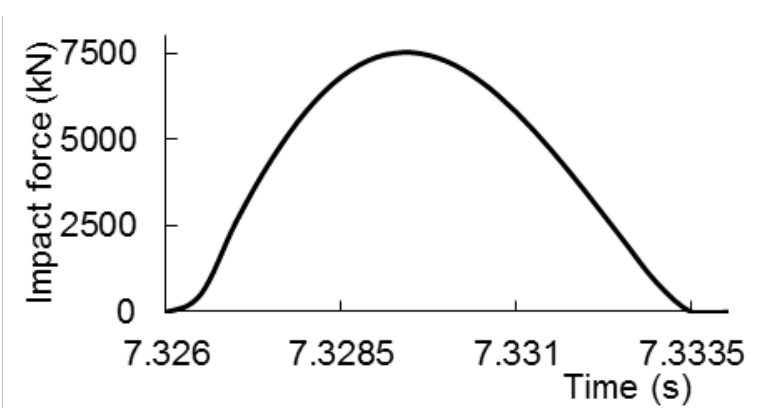

(b) Strongest impact

Figure 4. Impact force time history

Figure 4 confirms that the impact duration is short $(7.5 \mathrm{~ms}$, Figure $4 . \mathrm{b})$; this highlights the need of using extremely small discretization periods in the time integration. Another relevant remark is the high value of the maximum impact force. Figure 4.b shows that the time variation of the impact force is roughly shaped as a half sine-wave, this opposing the classical impact theory (subsection 2.2.2), which predicts constant force. Noticeably, the alternative formulation for estimating the damping parameter proposed in [Kharazian 2017] has been considered; this approach provides different duration for each collision, as detected in [Dimitrakopoulos et al. 2009a,b]. Conversely, the approach in [Anagnostopoulos 1988] yield uniform duration.

\subsubsection{Modified Kelvin-Voigt model}

The normal Kelvin-Voigt model is simple and accurate; its only inconsistency is a negative value of the pounding force $F$ occurring just before separation. In the modified model, this conflict is eliminated by removing the damping term when the relative velocity is negative. Therefore, first equation (6) is modified as

$$
F=k\left(x_{1}-x_{2}-d\right)+c\left(\dot{x}_{1}-\dot{x}_{2}\right) \text { if } \dot{x}_{1}-\dot{x}_{2} \geq 0 \quad F=k\left(x_{1}-x_{2}-d\right) \text { if } \dot{x}_{1}-\dot{x}_{2}<0
$$

The relation between damping ratio and restitution factor (equation (8)) is accordingly modified; two alternative expressions are provided: $\zeta=\frac{1}{\pi} \frac{1-r^{2}}{r}$ and $\zeta=\frac{1-r^{2}}{r(r(\pi-2)+2)}$. Then, the performance of the model is checked in a number of comparative analyses. The study [Mahmoud, Jankowski 2011] demonstrates that the results obtained through the modified model are similar to those of the normal one. The works [Komodromos et al. 2007; Kun et al. 2009a; Pant et al. 2010; Barros et al. 2013] propose other modifications of the Kelvin-Voigt model.

\subsection{Nonlinear viscoelastic model}

The nonlinear viscoelastic model was proposed by [Jankowski 2005] to simulate the structural pounding force more precisely by expanding the Hertz contact law into the viscoelastic domain. This model adds a nonlinear viscous damper to the nonlinear elastic model. As in the Modified KelvinVoigt model, the damper is active only when the masses approach each other, and thus the uniform damping and tensile force in the linear viscoelastic model are removed; equation (9) is modified as:

$$
F=k\left(x_{1}-x_{2}-d\right)^{\frac{3}{2}}+c\left(\dot{x}_{1}-\dot{x}_{2}\right) \text { if } \dot{x}_{1}-\dot{x}_{2} \geq 0 \quad F=k\left(x_{1}-x_{2}-d\right)^{\frac{3}{2}} \text { if } \dot{x}_{1}-\dot{x}_{2}<0
$$

The damping is given by $c=2 \zeta \sqrt{k \sqrt{x_{1}-x_{2}-d} \frac{m_{1} m_{2}}{m_{1}+m_{2}}}$, where $\zeta$ is the damping ratio being related to the restitution factor by $\zeta=\frac{9 \sqrt{5}}{2} \frac{1-r^{2}}{r(r(9 \pi-16)+16)}$ [Jankowski 2006a]. The objective of this model is to eliminate the jumps that appear in the modified Kelvin-Voigt model at the beginning and the end of the contact; this objective is reached, but the transition from deformation to restitution phase of contact 
is not smooth. Such discontinuities are avoided in the Hertzdamp model presented in the next subsection.

[Khatiwada et al. 2011] propose a modification of this model. The nonlinear behavior of the colliding buildings is represented by a perfect elastic-plastic model.

\subsection{Hertzdamp model}

This approach is proposed for pounding simulation in [Muthukumar, DesRoches 2006], although had been previously considered for multi-body systems [Lankarani, Nikravesh 1990]. This model consists in the parallel combination of a nonlinear Hertzian spring and a nonlinear viscous damper (dash-pot):

$$
\begin{gathered}
F=k\left(x_{1}-x_{2}-d\right)^{3 / 2}+\zeta\left(\dot{x}_{1}-\dot{x}_{2}\right)\left(x_{1}-x_{2}-d\right)^{3 / 2} \\
x_{1}-x_{2} \geq d
\end{gathered} \quad F=0 \text { if } x_{1}-x_{2}<d
$$

Equating the energy loss to the energy dissipated by the damper, an expression for $\zeta$ can be found: $\zeta=\frac{3 k\left(1-r^{2}\right)}{4\left(\dot{x}_{1}-\dot{x}_{2}\right)}$. Replacing $r=0$ in this equation, $\zeta \neq \infty$ is obtained; for this inconsistency, [Kun et al. 2009b] provided this modified version: $\zeta=\frac{8 k(1-r)}{5 r\left(\dot{x}_{1}-\dot{x}_{2}\right)}$. Noticeably, this result, although being coherent, does not arise from any consistent theoretical base. Then, [Khatiwada et al. 2014b] provided the following relation: $1+r=\frac{k}{\zeta\left(\dot{x}_{1}-\dot{x}_{2}\right)} \ln \frac{\frac{k}{\zeta\left(\dot{x}_{1}-\dot{x}_{2}\right)}+1}{\frac{k}{\zeta\left(\dot{x}_{1}-\dot{x}_{2}\right)}-r}$.

\subsection{Sears model}

[Khatiwada et al. 2013b; Khatiwada, Chouw 2014] propose using the Sears formulation [Sears, 1912] for pounding simulation. This approach is based on a series combination of lumped and distributed models, being initially developed for impact between circular bars with rounded ends. This model can overcome some limitations of the lumped and distributed ones. However, more experimental work is needed to calibrate the concentrated stiffness parameter. In its current version, the model does not include any damping; the theoretical development in subsection 2.2 might be useful.

\subsection{Concluding remarks}

The considerations in the previous subsections, highlight that, regarding the lumped impact models, the normal Kelvin-Voigt model is sufficient for most purposes; the modified Kelvin-Voigt model is more complex and does not provide any significant improvement. The models based on the Hertz contact law are not adequate, since that law was derived for elastic contact between balls; this situation being very different than the impact between slabs with straight ends. The Sears model looks promising, although further development is necessary. Concerning the distribution of the impact models along the building height, in most of the occasions, a single impact model in the top colliding level is sufficient, since impacts in the lower stories are rare (Figure 3.b); in general, such impacts are more frequent when the buildings are not separated $(d=0)$. In any case, it is recommended to check this circumstance before making the final choice. Regarding this issue, the work [Polycarpou et al. 2014] presents a methodology where the "a priori" determination of the contact points is not required.

One of the most relevant observations is the extremely short impact duration; this circumstance, together with the fact that the collision is mainly produced only at a single story, generates an important higher mode excitation. Therefore, the dynamic analyses require a short time step; this being emphasized by the nonlinearity of most of the analyses.

\section{POUNDING SIMULATION WITH SOFTWARE CODES}

\subsection{Simplified commercial codes}


This denomination refers to codes that are commonly used in earthquake engineering, mainly for professional use, i.e. designing and analyzing constructions in seismic areas. Although it is apparent that these programs are not research-oriented, they have been extensively used for that purpose, given that they are user-friendly, robust and reliable. Since this type of software is highly result-oriented, for research purposes they near constitute a black box; therefore, research use requires deep knowledge on the employed code. It is estimated that the learning time is approximately one month for an average non-experienced user. Since these codes (Etabs, GSA, Midas, Perform-3D, Risa, Robot, SAP, Sofistik, Staad, Strand7, Tekla, among others) are rather similar; only the Etabs code [Wilson et al. 1979] is discussed here.

Etabs. At a first glimpse, this software holds the capacity of simulating seismic pounding; however, a deeper review highlights several limitations. The most serious one is that, although the provided gap model can be series connected with the Kelvin-Voigt model, in nonlinear time history analysis, damping cannot be used in the model. Regarding the nonlinear behavior of the colliding buildings, it can be simulated with plastic hinges, both considering concentrated and distributed plasticity (fiber) models. If the behavior of the buildings near collapse is of interest, this software is not adequate, since not all the failure modes are adequately accounted for [Alfarah et al. 2017]; in other words, the provided capacity can be grossly overestimated. About the time discretization, any short time step (although constant) can be selected. Since it is not possible to modify the time step during the calculation time, nonlinear analyses are highly time-consuming. Another relevant limitation is that non-zero initial conditions cannot be imposed; this prevents, for example, analyzing the free damped response of any structure. In brief, this software is adequate for analysis of linear pounding, but is not for nonlinear pounding.

\subsection{Scientific codes}

This category includes software packages that have been developed inside Universities or Research Centers and, therefore, are oriented to teaching and, mainly, research. Noticeably, one of their main distinctive characteristics is that they are free for non-profit use. Although a wide number of codes exist (SeismoStruct, OpenSees, Ruaumoko, ZeusNL, IDARC, among others), only the first two are considered herein, being apparently the most spread ones. Given the research orientation of these programs, the "black box" part is significantly smaller than in the commercial codes.

SeismoStruct. This program belongs to the family SeismoSoft [SeismoSoft 2016], having been developed in the EU Center (University of Pavia, Italy). Although this software is able to simulate pounding, some relevant limitations must be cared about, as discussed next. The "Link Element" can be used as the Kelvin-Voigt model by defining the behavior as "Gap_ hk"; noticeably, the stiffness needs to be defined for each of the six degrees of freedom, despite the gap is actually uniaxial. Regarding this, some recommendations are provided for the selection of the stiffness in the other directions; such criteria are empiric (e.g. in between 100 and 200 times higher than the axial stiffness of the colliding slabs), and no further justification is provided. Conversely, only a single value is required for damping. The Hertzdamp model can be introduced manually. In nonlinear time-history analysis, the influence of the gravity loads is automatically accounted for. Regarding the time step, it cannot be reduced beyond a limit imposed by the size of the output files; this being in some cases a serious restriction. It is worth mentioning that in the newest versions (2016 Release 6), the output files corresponding to the previous versions cannot be completely read, thus preventing most of the postprocessing operations. On the simulation of the buildings nonlinear behavior, plastic hinges as basically treated as in Etabs, although there are more capacities. Although this program is not commercially-oriented, pre and post-processing is as user-friendly as in Etabs. As well, like in Etabs, non-zero initial conditions cannot be imposed. In a few words, this software holds most of the required capacities, although the relevance of the aforementioned limitations in each particular case should be accounted for. The learning time is about two months for an average non-experienced user. 
OpenSees. This program (Open System for Earthquake Engineering Simulation) [PEER 2015] is an object-oriented software being developed by the PEER (Pacific Earthquake Engineering Research Center), belonging to the University of California at Berkeley. One of the main advantages is the "Open" characteristic, this meaning the possibility of programming the issues that are not available, and even modifying the existing ones. Nonetheless, there is a wide and active community working in and developing the OpenSees code, this offering extensive support and help. Another relevant advantage lies in the inherent scientific nature of this software, being clearly research-oriented. Conversely, pre and post-processing are not as user-friendly as in commercial codes; obviously, some parallel software can be used for this purpose. Going into details, although there is no any specific element for the Kelvin-Voigt model, it can be generated by combining spring, dash-pot and gap elements; unfortunately, this can be rather cumbersome. As well, the Hertzdamp model can be also created in a similar way. For time integration, any short time step (although constant along the calculation duration) can be selected. The required learning time is longer than for SeismoStruct. Quickly, introducing into pounding simulation using this software can be a long and hard task; however, this effort can pay in most cases.

This paragraph discusses some comparisons between OpenSees and SeismoStruct. Both codes can process force-based or displacement-based elements; since in the first case mesh refinement does not improve the accuracy, a single element per member can be used. Conversely, in the displacementbased elements mesh refinement yields better accuracy, thus finer meshes might be worth using. In general, OpenSees is faster than SeismoStruct, unless the option of showing the results during the analysis is deactivated. Another relevant advantage of OpenSees is its superior ability for describing the nonlinear building behavior; when pounding is expected to generate high damage, this feature can be conclusive.

Figure 5 represents a comparison among pounding responses obtained using different discretization periods. The plotted results correspond to seismic pounding between two RC building frames with 5 and 3 stories, respectively [Kharazian 2017]. Figure 5.a shows a time window of the impact force time history, while Figure 5.b displays the cumulated hysteretic energy at each level of the 3-story frame. These results have been obtained with SeismoStruct [SeismoSoft 2016]; the impact is described with the Kelvin-Voigt model.

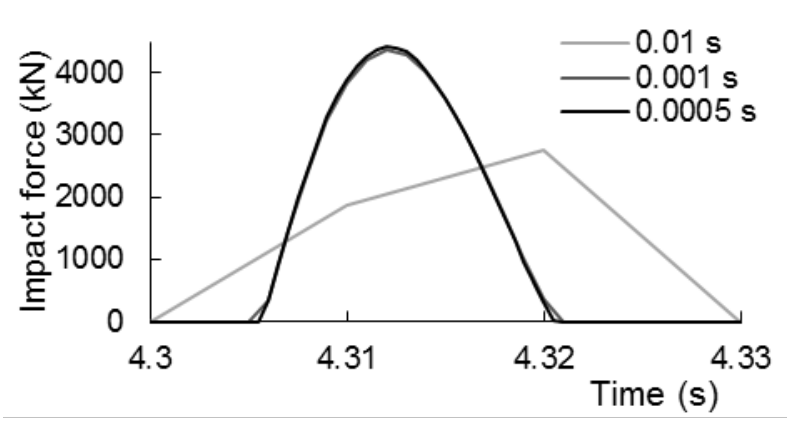

(a) Impact force time history

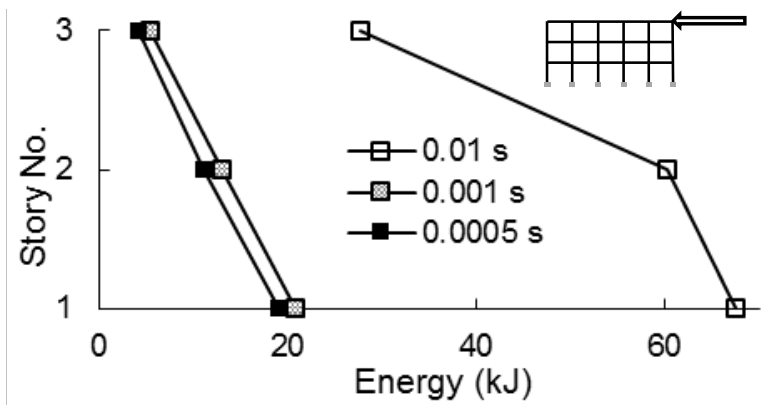

(b) Cumulated hysteretic energy at each story

Figure 5. Seismic pounding responses for a 3-story building frame

Figure 5 points out the difference in the results for different discretization periods; this highlights the need of using extremely small time steps in the time integration. Noticeably, in any nonlinear dynamic analysis, there no specific criteria for selecting the discretization period; it should be based on examining the responses for progressively reduced values of $\Delta t$. Regarding this issue, Figure 5 shows that the response for $\Delta t=0.01 \mathrm{~s}$ is clearly different than those for 0.001 and $0.0005 \mathrm{~s}$; since the results for these values are highly similar, it can be presumed that taking $\Delta t=0.0005 \mathrm{~s}$ is sufficient.

\subsection{Advanced codes}


This group comprises some software codes (Abaqus, Ansys, Diana, Nastran, among others) that are commonly recognized as advanced; regarding structural analysis, their capacities include continuum mechanics-based approaches, and use of implicit and explicit formulations for performing time integration. The implicit strategy is commonly implemented in simplified programs, for both static and dynamic analyses; it consists basically in inverting the stiffness matrix to obtain the structural response. In linear static analysis this operation is performed only one time; in nonlinear static analysis, iterations are required. In dynamic analysis, these operations are performed at each discretization instant; then it is apparent that such analyses can be highly time-consuming, both because of the iterations and the need of considering short time steps to guarantee convergence and accuracy. The explicit strategy is only considered for dynamic analysis; the stiffness matrix is not inverted, but the mass one is, this operation being significantly cheaper in terms of computational effort. At each time step the acceleration vector is obtained in terms of the velocity and displacement vectors (at that instant) through the equation of motion; then the velocity and displacement vectors at next instant are determined by numerical integration and derivation. Even if the analysis is nonlinear (i.e. the stiffness matrix is not constant), there is no need for iteration; conversely, for a proper accuracy, the time step needs to be shorter than in the implicit case. In spite of this, the explicit formulation is usually faster than the implicit one because there is no need for repeated and cumbersome matrix inversions, and there are no iterations, this largely compensating the shorter time step. The explicit formulation can be recommended for pounding, since the time step must be short anyway, given the relevant participation of the high modes and the extremely brief impact duration. Nevertheless, it should be kept in mind that this formulation is dangerous, since the solution is always obtained, but it is unclear that it is correct. Noticeably, the explicit formulation can be also implemented in OpenSees.

Although these codes are somehow research-oriented, the fact that they are more powerful than the previous ones implies also a bigger black box. Regarding the learning time, it ranges between three to four months for an average non-experienced user.

The application of the two mostly used software packages (Abaqus [Hibbett et al. 1998] and Ansys [ANSYS 2016]) for pounding simulation is discussed next.

Abaqus. There is one element for the normal Kelvin-Voigt model, being termed "Axial Element”. This element can be used in both linear and nonlinear analyses; noticeably, this possibility is a relevant advantage compared to Etabs and similar codes. Another interesting feature is that the discretization period can be variable along the calculation time. This option is useful for better convergence in nonlinear analysis; in pounding simulation, the time step can be significantly shortened during impact. Regarding this, the impact can be anticipated, and then the time step is automatically reduced. The analysis can be interrupted and continued after the previous final state as many times as needed. Concerning the simulation of the nonlinear behavior of the colliding building, all the common formulations (plastic hinges described with concentrated and distributed plasticity, fiber models, continuum mechanics) can be implemented. Some issues can be programmed and implemented by the user, although more limitations than in OpenSees apply. In short, the use of this software for pounding simulation is recommended.

Ansys. The situation is similar to Abaqus; with all their relevant capacities being also active. The element "Combine 14" is useful for simulating the Kelvin-Voigt model. Currently (mid 2017), two versions of Ansys code are available, namely APDL and Workbench; they are better suited for research and commercial uses, respectively. Apparently, Workbench is being more promoted, with frequent updates and enhanced capacities. To sum up, the use of this software is also recommended.

\subsection{Concluding remarks}

This subsection summarizes the previous ones, aiming to provide advice on the most suitable software for each occasion. This decision is not straightforward, since several months are usually required for 
initial learning. As well, it is worth mentioning that forums, blogs, and other help sources are not always useful, since pounding simulation is a complicated and rather unusual task.

The herein provided recommendations refer to pounding simulation using lumped models. Regarding distributed models, the axial vibrations (subsection 2.2) can be simulated by fine discretization of each slab using virtually any software. Obviously, in this case, the rigid diaphragm effect should not be imposed.

Given the aforementioned major limitation of Etabs (damping cannot be incorporated in nonlinear time history analysis), its use is recommended only if the buildings behavior remains linear. Apparently, this limitation does not hold for Robot.

Regarding OpenSees, its high reliability and "open” character are extremely useful. As well, there is a wide and highly active community of users and developers, thus leading to continuous improvements.

The use of advanced software is only recommended either for previously experienced users or for those requiring high accuracy. The system requirements (RAM, CPU etc.) should be also taken into consideration.

Regarding the use of user-developed software codes in pounding simulation, the main difficulty does not lie in the pounding itself, but on the nonlinear behavior of the buildings. Therefore, if such a software is available, the programming of any of the models described in section 2 is quite affordable. Noticeably, a considerable number of the published researches use their own codes.

\section{LITERATURE REVIEW}

\subsection{Initial explanations}

This section presents a critical review of the technical literature on seismic pounding between RC buildings with aligned slabs. The discussed papers are grouped into several categories: observed damage, particular and parametrical studies, testing, input effect, influence of soil-structure interaction, mitigation, and review. Some papers on pounding between bridge slabs or between an isolated building and the moat wall are also discussed, given their interest for the subject under consideration.

\subsection{Observed damage from pounding}

A number of papers [Rosenblueth 1986; EERI 1989; EQE 1994; Comartin et al. 1995; Kasai, Maison 1997; Weimin 2000; Anagnostopoulos, Karamaneas 2008; Doğan, Günaydin 2009; Cole et al. 2012; Chouw, Hao 2012; Shakya, Kawan 2016; Kagermanov et al. 2017] contain comprehensive descriptions of damaged buildings under pounding effect. These studies highlight the relevance of this issue, since damages are severe, being responsible for a significant percentage of the observed collapses.

\subsection{Particular and parametrical studies}

- [Anagnostopoulos 1988]. This paper describes a parametrical study on pounding amongst arrays of adjoining buildings. It is shown that the end structures experience almost always substantial increases in their response while for 'interior' structures the opposite often happens. This statement matches with the observed damage.

- [Anagnostopoulos, Spiliopoulos 1992]. This paper investigates the response of adjacent pounding buildings. Collisions are simulated by means of Kelvin-Voigt models. It is found that pounding can cause high overstresses, mainly when the colliding buildings have significantly different heights, periods or masses. The authors show that the restitution factor ranges between 0.5 and 0.75 . 
- [Maison, Kasai 1990]. This paper analyzes the pounding between an actual 15-story building and a shorter and rigid adjacent building. It is concluded that the effect in the stories above the pounding location is significant.

- [Maison, Kasai 1992]. This paper investigates the floor-to-floor pounding between two 15 and 8storey buildings. The influence of building separation, relative mass, and contact location properties are assessed. Apart from the remarks in subsection 2.3, it is concluded that the drifts in the tallest buildings are increased while are decreased in the shortest one, except in the stories in the vicinity of the impact. Regarding the building mass, the higher the difference, the more the adverse effect on the less massive building.

- [Papadrakakis et al. 1996]. This paper studies the three-dimensional pounding between two or more buildings. The effects of various in-plan configurations are investigated for two real earthquake motions. It is concluded that pounding affects the stiffest structure and reduces the demand on the flexible one, particularly when the excitation is near the resonance of the flexible building.

- [Pantelides, Ma 1998]. The structural response of SDOF models with either elastic or inelastic structural behavior is analyzed. Pounding is modeled as a Hertz impact force. For colliding structures with different periods, similar earthquake excitations can produce different responses.

- [Jeng, Tzeng 2000]. This paper analyzes the pounding vulnerability of actual buildings in Taipei. It is concluded that pounding mitigation is necessary for a large number of buildings.

- [Chau, Wei 2001]. This paper analyzes the pounding, under harmonic excitation, between two structures. It is shown that, as expected, the impact velocity increases drastically when the difference in natural periods between the two structures increases, being relatively insensitive to the gap size. The maximum impact velocity can occur at an excitation period either between those of the two oscillators or less than both of them.

- [Karayannis, Favvata 2005]. This paper deals with the interaction between RC buildings with non-equal heights and with both aligned and unaligned slabs. The columns ductility requirements are bigger where the gap is smaller, mainly in the columns of the tallest building.

- [Jankowski 2006b]. This paper proposes the concept of impact force response spectrum, e.g. peak pounding force vs. natural period. It is concluded that gap, natural period, damping, mass, ductility, and input time lag might have a substantial influence.

- [Jankowski 2008b]. This paper presents an investigation on pounding between two equal-height buildings with different dynamic properties. Results show that the collision significantly influences the lightest and more flexible building, whereas the heaviest and stiffest structure is affected only negligibly.

- [Bothara et al. 2008]. This paper studies the pounding vulnerability of actual buildings in Wellington. The authors show that pounding has become a major issue in many areas of the city.

- [Pant et al. 2010]. This paper simulates pounding between 8 and 10-story framed RC buildings using the modified Kelvin-Voigt model. It is shown that the response of the 8-story building is amplified and that the response is more dependent on the input characteristics than on the gap.

- [Boyer et al. 2012]. The impact between two SDOF models is analyzed. Different coefficients of restitution, gap distances and periods are considered. It is concluded that the impact probability increases as the gap decreases and the structural period differences increase.

- [Chase et al. 2015]. This paper presents a pounding risk probabilistic study. It is shown that small gaps, different structural periods, great coefficients of restitution, and structural linearity lead to higher impact probability.

- [Zhai et al. 2015]. Pounding between multi-story building models with bilinear behavior is investigated through dimensional analysis. The pounding effect is illustrated with three spectral regions (amplified, de-amplified and unaffected). Results show that the influence of the stiffness ratio is more significant for the lightest and more flexible building in the first spectral region; also, for the heaviest and stiffest building, the pounding force and the velocity are sensitive to the mass ratio.

- [López-Almansa, Kharazian 2014; Kharazian, López-Almansa 2017]. These works present preliminary results of pounding between 3 and 5-story RC frames. Pounding is modeled using Kelvin-Voigt models. 
- [Elwardany et al. 2017]. This paper analyzes the effect of infill panels on the seismic pounding of adjacent steel structures in series. The results show that the infill panels can significantly change the seismic behavior.

The first remark is that pounding is serious, as concluded from subsection 4.2. Another relevant observation is that, in an array of several buildings, the end ones are the most damaged; therefore, the most representative and critical situation is the collision between two buildings. Regarding this, pounding is more severe when the buildings periods are different, given that the possibilities of encounters grow. Moreover, in that case, pounding behavior becomes chaotic, even for harmonic excitation. Another issue that worsens pounding is the difference in height, because of the whiplash effect of the protruding floors of the tallest building. Some researches point out that, in collisions between buildings with different mass and stiffness, the lightest and more flexible building is more affected. Concerning the gap influence, obviously, beyond a certain value, there is no pounding; apart from this, its influence is not intense. Finally, the buildings nonlinear behavior can be basically treated as a stiffness reduction. The influence of the input characteristics is discussed in subsection 4.5.

Figure 6 presents a comparison between the maximum drift angles of a 5-story RC building frame in two conditions: pounding with a 3-story frame, and no pounding [Kharazian 2017]. The plotted drift angles are the average of the maximum responses for a number of seismic inputs; both negative (left) and positive (right) maxima are displayed. These results have been obtained with SeismoStruct [SeismoSoft 2016]; the impact is described with a Kelvin-Voigt model connecting the third floors of both buildings.

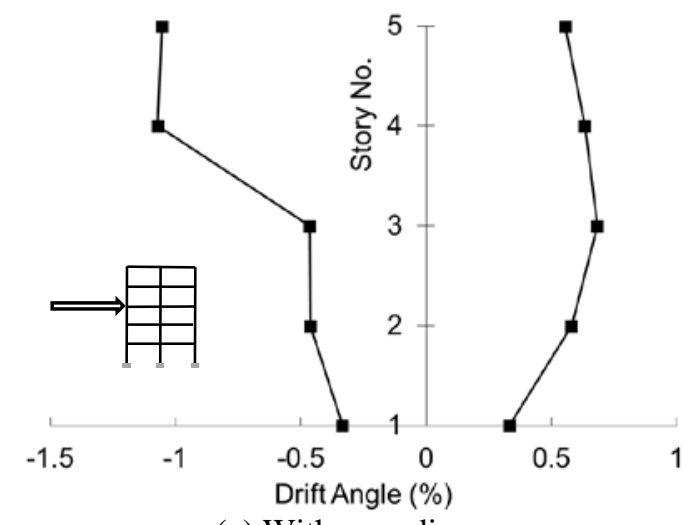

(a) With pounding

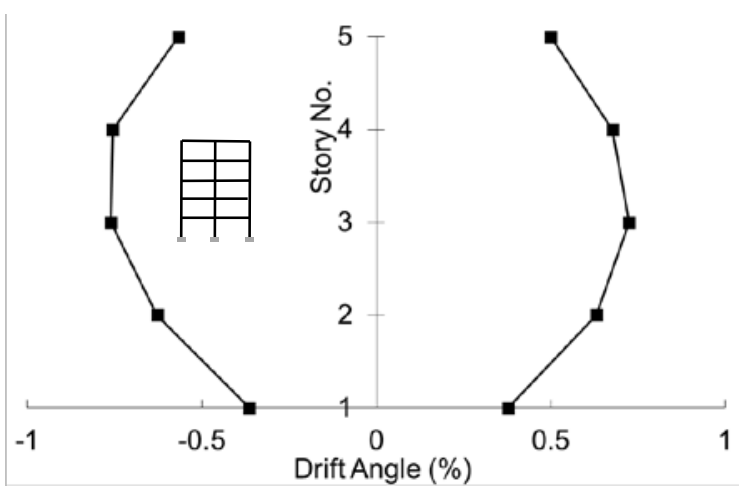

(b) Without pounding

Figure 6. Maximum drift angle with / without pounding of a 5-story RC building frame

Figure 6 shows that pounding has a significant effect, mainly on the left maximum drift in the stories near the impact location. This circumstance fits previous observations.

\subsection{Testing on pounding}

- [Van Mier et al. 1991]. This paper describes a series of experiments on the impact between two concrete elements. In all the cases, a sharp-ended striker impacted on a prestressed concrete pile with constant section. Detailed information on the impact force time-history are provided.

- [Papadrakakis, Mouzakis 1995]. In this paper, shaking table pounding experiments between same-height two-story RC building frames are carried out. Displacement, acceleration, and input energy time histories are presented.

- [Filiatrault et al. 1996]. This work refers to shaking-table pounding experiments between two reduced scale 3 and 8-story steel frames. Among other results, time-histories of the impact force are provided. 
- [Zhu et al. 2002]. This paper describes shaking table 1-D and 2-D pounding experiments between two reduced-scale steel bridge decks and between a bridge deck and an abutment. Displacement time-histories are reported.

- [Chau et al. 2003]. Shaking table pounding tests between two steel towers with different natural frequencies, damping ratios and separations have been carried out. Input harmonic waves and seismic ground motions are used. It is observed that chaotic motion develops when the difference between the two natural frequencies of the towers are large. Under sinusoidal excitations, the maximum impact velocity develops at an excitation frequency between both natural frequencies. Pounding amplifies the response of the stiffest structure but reduces that of the more flexible one.

- [Rezavandi et al. 2007]. Two series of shaking table experiments on small-scale one-bay frames subjected to harmonic and seismic excitation are described. Techniques of reduction of pounding effects are presented: distance increase, absorbing material, and buildings connecting.

- [Jankowski 2008a]. The accuracy of pounding models (section 2) is checked by comparison with an impact experiment conducted by dropping balls of different building materials.

- [Jankowski 2010]. The author compares the results of two pounding experiments between elements made of steel, concrete, timber, and ceramic. The results show that the restitution factor depends significantly on the impact velocity and on the material of the colliding elements.

- [Khatiwada et al. 2013a]. This study describes shaking table pounding experiments between two steel frames without any seismic gap. It is observed that the pounding effect is more sensitive to the difference in natural periods than in mass.

- [Khatiwada et al. 2013b]. This paper presents experiments on pounding between two suspended reinforced concrete slabs. Time histories of the impact forces are reported. The experimental results are compared with the predictions of the most common numerical models.

- [Khatiwada et al. 2014]. The same tests described in [Khatiwada et al. 2013b] are discussed in this work. Experimental results on peak acceleration, restitution factor and impact force are presented and commented. The effects of impact velocity, mass ratio and geometry of the colliding surfaces are investigated.

- [Guo et al. 2012, 2015]. These papers describe shaking table pounding experiments between two reduced-scale steel bridge decks. Time-histories of acceleration, displacement and impact force are reported. It is observed that a perfect surface-to-surface contact cannot be easily achieved.

- [Jankowski et al. 2015]. Shaking table experiments on pounding between steel towers in series are described. This study shows the influence of pounding on the behavior of structures in series.

- [Sasaki et al. 2017]. This paper describes a full-scale shake table experiment of impact between a base-isolated building and the wall.

Experimental results on concrete-to-concrete slab impact are rather scarce. Most of the researches highlight the difficulty of obtaining precise measurements, given the high-frequency motion during the impact; some studies suggest that accelerometers should be complemented with acoustic signal sensors and video recorders. Nowadays many open questions still remain. Noticeably, given the scarcity of experimental results in full-scale buildings, distributed-parameter models can be used instead, since they provide results that are closer to reality than those from the most simplified methods.

\subsection{Input effect}

- [Dimitrakopoulos et al. 2009a,b]. The pounding response under pulse-type and arbitrary excitations is analyzed. Concerning the pulses, it is shown that regardless of the maximum acceleration and the duration of the pulse, the response spectra are similar. The study confirms the existence of three spectral regions. The response of the most flexible/stiffest oscillator amplifies in the low/high-frequency range. The study shows that pounding structures may be most vulnerable to frequencies very different from their natural ones. The study also unveils that the dimensionless response exhibits an incomplete self-similarity with respect to the mass ratio. Regarding the arbitrary inputs, the study proposes input selection criteria and shows that the proposed approach reduces drastically the scatter in the response. 
- [Yaghmaei et al. 2012]. The effect of mass, gap, and damping on pounding response under near and far-field inputs is studied. Some exceptions to the common acceptance that the pounding force decreases with the gap increase are found.

- [Efraimiadou et al. 2013]. The effect of multiple earthquakes on the collision between planar RC 5 and 8-storey building frames is examined.

- [Polycarpou et al. 2015]. The effect of the input incidence angle investigated. In many cases, pounding becomes more pronounced for excitation angles different from 0 or 90 degrees.

- [Mavronicola et al. 2017]. This paper describes 3-D parametrical studies on the pounding effect on base-isolated structures. The study shows that the influence of the input incidence angle and the mass eccentricity is significant.

- [Kharazian 2017]. A parametric study on the pounding response of 3 and 5-story RC buildings is conducted. Regarding the input influence, it is assumed that their most relevant characteristics are the importance of velocity pulses and the frequency content (represented by the soil type).

These studies point out that the seismic input effect is significant. This remark is based on the rather chaotic nature of the pounding response and on the high diversity of the ground motion characteristics. A relevant conclusion is that any parametric study should consider the actuation of a wide and representative set of accelerograms. Their main features are: relevance of velocity pulses (near-fault effects), soil type, earthquake magnitude, distance to the center, and duration.

Figure 7 displays time histories of impact force in the seismic pounding between two RC building frames with 3 and 5 stories, respectively [Kharazian 2017]. Figure 7.a and Figure 7.b correspond to different historic ground motions; one of them does not have near-fault effects and is recorded in soft soil while the other one has relevant near-fault effects and is recorded in stiff soil. These results have been obtained with SeismoStruct [SeismoSoft 2016]; the impact is described with a Kelvin-Voigt model connecting the third floors.

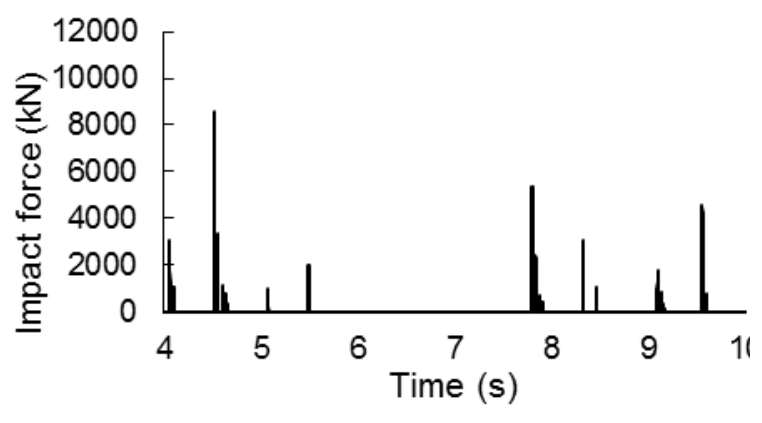

(a) Non pulse-like input. Soft soil

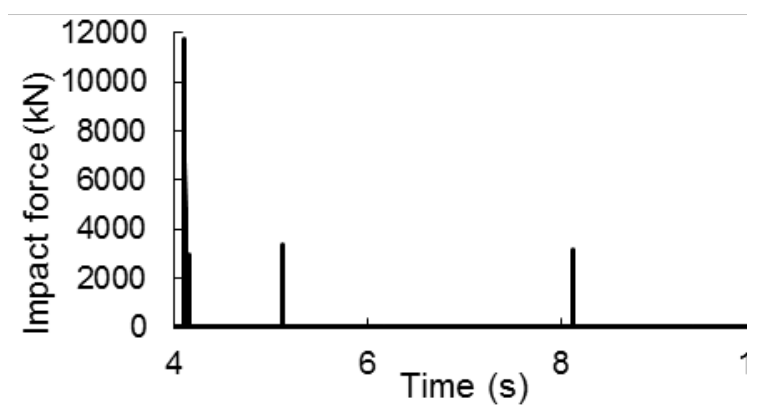

(b) Pulse-like input. Stiff soil

Figure 7. Impact force time histories

Figure 7 shows that, although both inputs have similar Arias intensity [Kharazian 2017], the impact force histories are completely different. This highlights the influence of the input characteristics.

\subsection{Influence of Soil-Structure Interaction (SSI)}

- [Schmid, Chouw 1992]. SSI is described with boundary and finite element solutions. It is concluded that SSI has a profound influence on the impact behavior.

- [Rahman et al. 2001]. This paper studies pounding between RC buildings considering the soil flexibility. The pounding response is found to be highly sensitive to the SSI and to the characteristics and direction of the seismic excitation.

- [Chouw 2002]. This paper analyzes the influence of soil-structure interaction on the pounding response of adjacent buildings under-source earthquakes. The results show that both SSI and pulses have a significant effect. 
- [Chouw, Hao 2005]. This paper studies the influence of the SSI and the spatial ground motion on the pounding of two adjacent bridge frames. The authors concluded that both issues should be considered.

- [Naserkhaki et al. 2012]. This paper examines pounding between adjacent buildings with SSI. Results indicate that the underlying soil negatively impacts the buildings seismic responses.

- [Mahmoud et al. 2013]. This paper examines the SSI effect on pounding between two equalheight inelastic buildings. It is found that SSI decreases the drift, the impact force and the dissipated energy, whereas increases the acceleration.

- [Madani et al. 2015]. This paper simulates and discusses the effects of pounding and SSSI between two adjacent steel structures. The study shows that this issue is relevant.

- [Kharazian 2017]. A parametric study on the pounding response of 3 and 5-story RC buildings is conducted. SSI is represented by springs and dashpots; two types of foundation are contemplated, namely isolated and mat.

These studies show that SSI cannot be neglected in seismic pounding simulation.

Figure 8 displays a comparison between the pounding responses of two building frames with 3 and 5 stories by considering and neglecting the soil-structure interaction, respectively [Kharazian 2017].

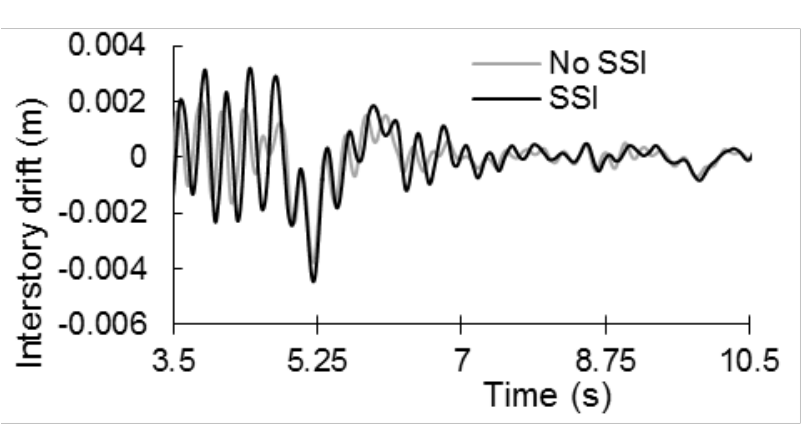

(a) Third floor drift in the 3-story frame

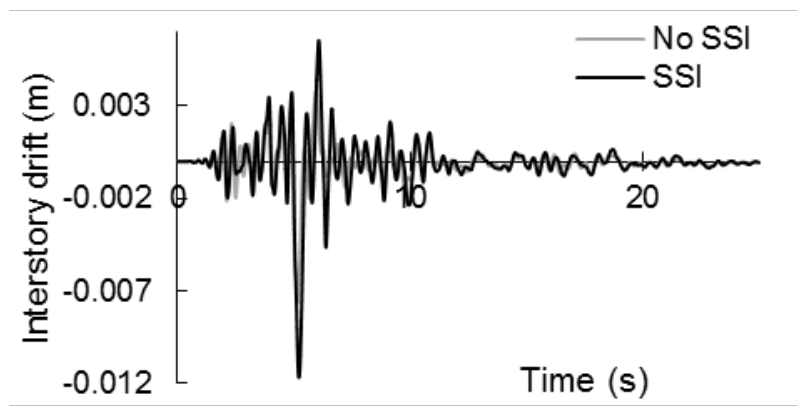

(b) Third floor drift in the 5-story frame

Figure 8. Interstory drift time histories with and without SSI

Figure 8 shows that the effect of the SSI is significant, thus confirming the conclusions of most of the previous studies.

\subsection{Mitigation}

- [Valles, Reinhorn 1997]. Apart from other contributions, this paper describes three types of elements for pounding mitigation: link, bumper, and damper.

- [Ruangrassamee, Kawashima 2003]. This research shows the effectiveness of variable dampers in improving the seismic pounding response of bridges.

- [Anagnostopoulos, Karamaneas 2008]. The use of bumper shear walls to minimize the damage of RC buildings is investigated. Results indicate that pounding keeps within tolerable limits and the collision walls will suffer repairable local damage.

- [Guo et al. 2009]. This paper presents an experimental and analytical study on pounding reduction of highway bridges subjected to earthquake ground motions by using magnetorheological dampers with semi-active control. It is concluded that the dampers mitigate the pounding effect.

- [Polycarpou et al. 2013]. This work describes the incorporation of rubber bumpers between adjacent buildings and proposes a simulation model.

- [Takabatake et al. 2014,2015; Khatiwada et al. 2015]. These papers present an effective method for reducing the pounding damage. The method involves inserting a shock-absorbing material into the joint gap. Numerical and experimental results confirm the effectiveness of the proposed approach, although some concerns arose.

- [Naderpour et al. 2017]. In this paper, an artificial neural network is used to estimate the required distance to prevent collision. The accuracy of the proposed formulation is numerically investigated. 
These investigations highlight the feasibility of using simple rubber bumpers for mitigation of seismic pounding between adjoining buildings as an alternative to the seismic separation requirements.

\subsection{Review}

- [Anagnostopoulos 1996]. A detailed review is presented. It is concluded that for buildings with similar height and structural characteristics, the pounding effects are limited to some local damage and to higher accelerations. Only when the buildings have much different masses, periods and heights, can pounding be a threat to safety. When the buildings masses are similar, the responses of the stiffest/softest buildings will be amplified/deamplified. Bumper shear walls are suggested.

- [Cole et al. 2010]. Current methods of building pounding assessment are reviewed. Critical building weaknesses vulnerable to pounding are presented.

\subsection{Base isolation}

- [Komodromos et al. 2007]. This paper describes seismic pounding of isolated buildings with the moat wall. It is shown that accelerations are significantly increased, especially at the base floor. Higher modes of vibration are excited, thus increasing the drift in the superstructure. The impact model stiffness significantly affects the acceleration, and has less effect on the displacement. It is also concluded that high isolation flexibility may generate pounding vulnerability.

- [Kun et al. 2009a]. This paper examines the suitability of the modified Kelvin impact model for simulation of pounding of base-isolated buildings. The conclusions are similar to those of [Komodromos et al. 2007].

- [Polycarpou, Komodromos 2010a,b,2011]. These papers investigate pounding of isolated buildings either with the moat wall or against adjacent buildings. The simulations reveal that even if a sufficient gap is provided, this does not ensure that the building will not collide with neighboring buildings. The use of rubber bumpers is considered.

- [Masroor, Mosqueda 2012]. Experiments were performed to assess the performance of seismically isolated buildings, including pounding against a moat wall. The impact forces depend significantly on the gap size, the impact velocity and the wall flexibility; in extreme cases, pounding can induce yielding in the superstructure.

- [Pant et al. 2012]. This paper describes the effect of pounding on base-isolated RC buildings excited with inputs containing velocity pulses. Given that the high uncertainty of the structural parameters of the isolator units, the influence of their upper and lower bounding values is analyzed.

- [Barros et al. 2013]. This paper compares pounding of base-isolated and fixed-base buildings. The authors conclude that the largest impact force appears in the top story, and that most of the damage corresponds also to fixed-base buildings.

- [Liu et al. 2014]. A linear impact model to predict the impact response of seismic isolated structures is proposed. The equivalent linear stiffness is theoretically derived. The effectiveness of this model is verified by comparing the numerical results with experimental ones.

\subsection{Bridges}

- [Malhotra 1998]. The theoretical results of the first part of this paper are used to analyze the pounding of segments of concrete bridges. The restitution factor is determined after recorded data. It is shown that pounding generally reduces the column forces, the large impact forces generated in the superstructure are not transmitted to columns and foundations, and pounding does not increase the longitudinal separation at hinges.

- [Jankowski et al. 1998]. The aim of this paper is to analyze pounding between the superstructure segments of an isolated bridge. The results of the study show that pounding leads to either the increase or decrease of the forces acting on piers, depending on the gap size between the superstructure segments. 
- [Ruangrassamee, Kawashima 2001]. This research investigates pounding between bridge segments. The results are represented in form of relative displacement response spectra.

- [Des Roches, Muthukumar 2002]. The response of multiple-frame bridges considering one and two-sided pounding is investigated. The relevance of the frame period and the ground motion characteristic period is shown. It is recognized that one-sided pounding amplifies the frame response of highly out-of-phase frames, mainly in short period structures; the two-sided pounding response has been increased in stiff frames.

- [Li et al. 2012]. This research evaluates experimentally the influence of spatial variation of ground motions on the pounding behavior of three adjacent bridge segments. The investigation is performed using three shaking tables. Results confirm that the spatially non uniform ground motions increase the relative displacement of adjacent bridge girders and pounding forces.

- [Marin 2014]. A modified Kelvin-Voigt model where frictional forces are involved is developed and implemented in OpenSees. This model is experimentally validated.

- [Chanda et al. 2016]. This paper analyzes seismic pounding between bridge segments using multi-body dynamics.

Given the big differences between pounding of buildings and bridges, the conclusions of these studies cannot be directly extrapolated to collision between adjoining buildings. The most relevant issues refer to numerical modeling.

\section{CONCLUSIONS}

This paper presents a review on the state-of-the-art of research on seismic pounding between buildings with aligned slabs. A summary of the theoretical developments is presented, the most common simulation software codes are examined, and an overview of the previous research is provided. The most relevant observations arising from this study are discussed next.

Next list contains a number of recommendations to new researchers, scholars, and professionals:

- The soil-structure interaction should be taken into consideration; neglecting their effects can lead to significant inaccuracies.

- If general conclusions are sought, do not consider a single seismic input; conversely, a representative set of inputs shall be utilized.

- To assess the pounding relevance, all the relevant response parameters should be examined: drift displacement, story shear force, absolute acceleration, impact force, absorbed energy, etc.

- In the numerical analyses, it is important to pay attention to the software selection; the indications in section 3 can be useful.

- In pounding simulation, it is basically suggested to utilize the normal Kelvin-Voigt model.

- In the time integration, it is important to use extremely short time steps, given the high frequencies involved in the collision.

Some research needs are listed next:

- Given the scarcity of fully reported experimental results, additional testing should be performed. Such tests must provide comprehensive information on the buildings response during impact.

- Regarding the numerical simulation, empirical criteria for selecting the time discretization might be extremely useful.

- Concerning the pounding relevance, because of its complexity and chaotic nature, a considerable number of studies about their consequences are still required.

- Since both distributed and concentrated models have serious limitations, developing the Sears model can be useful. Possible extensions are the incorporation of damping and the derivation of better strategies for estimation of the stiffness parameter.

\section{ACKNOWLEDGEMENTS}


This work has received financial support from Spanish Government under projects BIA2014-60093-R, MAT2014-60647-R and CGL2015-6591. These supports are gratefully acknowledged.

\section{REFERENCES}

Alfarah B, López-Almansa F, Oller S. (2017). Importance of non-simulated failure modes in incremental dynamic analysis (IDA) of non-ductile RC frames. 16WCEE, Santiago, Chile.

Anagnostopoulos SA. (1988). Pounding of buildings in series during earthquakes. Earthquake Engineering \& Structural Dynamics, 16(3):443-456.

Anagnostopoulos SA. (1996). Building pounding re-examined: how serious a problem is it. 11WCEE, Acapulco, México.

Anagnostopoulos SA. (2004). Equivalent viscous damping for modeling inelastic impacts in earthquake pounding problems. Earthquake Engineering \& Structural Dynamics, 33(8):897-902.

Anagnostopoulos SA, Karamaneas CE. (2008). Collision shear walls to mitigate seismic pounding of adjacent buildings. 14WCEE, Beijing.

Anagnostopoulos SA, Spiliopoulos KV. (1992). An investigation of earthquake induced pounding between adjacent buildings. Earthquake Engineering \& Structural Dynamics, 21(4):289-302.

ANSYS ${ }^{\circledR}$ (2016) Academic Research, Release 16.2, Help System, Coupled Field Analysis Guide, ANSYS, Inc.

Arias A. (1970). A measure of earthquake intensity. Seismic Design for Nuclear Power Plants. MIT Press, 438443.

ASCE/SEI 7-10. (2010). Minimum design loads for buildings and other structures. American Society of Civil Engineers.

ATC-40. (1996). Seismic Evaluation and Retrofit of Concrete Buildings. Applied Technology Council.

Barros RC, Khatami SM. (2013). Damping ratios for pounding of adjacent buildings and their consequence on the evaluation of impact forces by numerical and experimental models. Mecânica Experimental, 22:119-131.

Barros RC, Naderpour H, Khatami SM, Mortezaei A. (2013). Influence of seismic pounding on RC buildings with and without base isolation system subject to near-fault ground motions. Journal of Rehabilitation in Civil Engineering, 1(1):39-52.

Bothara JK, Jury RD, Wheeler K, Stevens C. (2008). Seismic Assessment of Buildings in Wellington: Experiences and Challenges. $14^{\text {th }}$ WCEE. Beijing.

Boyer F, Labrosse G, Chase JG, Rodgers GW, MacRae GA. (2012). Effects of coefficient of restitution, structural yielding and gap ratios on the impact mechanics of building pounding. $15^{\text {th }}$ WCEE, Lisbon.

Chanda A, Banerjee A, Das R. (2016). The Application of the most suitable Impact Model(s) for simulating the Seismic Response of a Straight Bridge under Impact due to Pounding. International Conference on Modern Engineering, Kerala, India.

Chase J, Boyer F, Rodgers G, Labrosse G, MacRae G. (2015). Linear and Nonlinear Seismic Structural Impact Response Spectral Analyses. Advances in Structural Engineering, 18(4):555-570.

Chau KT, Wei XX. (2001). Pounding of structures modeled as non-linear impacts of two oscillators. Earthquake Engineering \& Structural Dynamics, 30(5):633-651.

Chau KT, Wei XX, Guo X, Shen CY. (2003). Experimental and theoretical simulations of seismic poundings between two adjacent structures. Earthquake Engineering \& Structural Dynamics, 32(4):537-554.

Chopra AK. (2012). Dynamics of structures. Prentice-Hall.

Chouw N. (2002). Influence of soil-structure interaction on pounding response of adjacent buildings due to nearsource earthquakes. Journal of Applied Mechanics, 5:543-553.

Chouw N, Hao H. (2005). Study of SSI and non-uniform ground motion effect on pounding between bridge girders. Soil Dynamics and Earthquake Engineering, 25(7):717-728.

Chouw N, Hao H. (2012). Pounding damage to buildings and bridges in the 22 February 2011 Christchurch earthquake. International Journal of Protective Structures, 3(2):123-140.

Cole G, Dhakal RP, Carr AJ, Bull D. (2009). The effect of diaphragm wave propagation on the analysis of pounding structures. COMPDYN 2009 Conference, Rhodes, Greece.

Cole G, Dhakal RP, Carr AJ, Bull D. (2010). Building pounding state of the art: Identifying structures vulnerable to pounding damage. 2010 NZSEE Conference, Wellington, New Zealand.

Cole G, Dhakal R, Carr A, Bull D. (2011). An investigation of the effects of mass distribution on pounding structures. Earthquake Engineering \& Structural Dynamics, 40(6):641-659.

Cole GL, Dhakal RP, Turner FM. (2012). Building pounding damage observed in the 2011 Christchurch earthquake. Earthquake Engineering \& Structural Dynamics, 41(5):893-913.

Comartin CD, Greene M, Tubbesing SK. (1995). The Hyōgo-ken Nanbu Earthquake: Great Hanshin Earthquake Disaster, January 17, 1995: Preliminary Reconnaissance Report. Earthquake Engineering Research.

Correia AA, Virtuoso FBE. (2006). Nonlinear analysis of space frames. III European Conference on Computational Mechanics, Lisbon. 
DesRoches R, Muthukumar S. (2002). Effect of pounding and restrainers on seismic response of multiple-frame bridges. Journal of Structural Engineering, 128(7):860-869.

Dimitrakopoulos E, Kappos AJ, Makris N. (2009). Dimensional analysis of yielding and pounding structures for records without distinct pulses. Soil Dynamics and Earthquake Engineering, 29(7):1170-1180.

Dimitrakopoulos E, Makris N, Kappos AJ. (2009). Dimensional analysis of the earthquake induced pounding between adjacent structures. Earthquake Engineering \& Structural Dynamics, 38(7):867-886.

Doğan M, Günaydin A. (2009). Pounding of adjacent RC buildings during seismic loads. Journal of Engineering and Architecture Faculty of Eskişehir Osmangazi University, 22(1).

EERI. (1989). Loma Prieta earthquake. October 17, 1989.

Efraimiadou S, Hatzigeorgiou GD, Beskos DE. (2013). Structural pounding between adjacent buildings subjected to strong ground motions. Part I: The effect of different structures arrangement. Earthquake Engineering \& Structural Dynamics, 42(10):1509-1528.

Elwardany H, Seleemah A, Jankowski R. (2017). Seismic pounding behavior of multi-story buildings in series considering the effect of infill panels. Engineering Structures, 144:139-150.

EQE. (1994). The January 17, 1994 Northridge, California Earthquake, An EQE Summary Report. Retrieved from http://www.absconsulting.com/resources/Catastrophe_Reports/1994 Northridge EQ.pdf.

Filiatrault A, Wagner P, Cherry S. (1996). An experimental study on the seismic pounding of buildings. 11 WCEE, Acapulco, México.

Goldsmith W. (1960). Impact: The theory and physical behavior of colliding solids. Arnold.

Graff K F. (1975). Wave motion in elastic solids. Courier Corporation.

Guo A, Li Z, Li H, Ou J. (2009). Experimental and analytical study on pounding reduction of base-isolated highway bridges using MR dampers. Earthquake Engineering \& Structural Dynamics, 38(11):1307-1333.

Guo AX, Cui LL, Li H. (2012). Impact stiffness of the contact-element models for the pounding analysis of highway bridges: experimental evaluation. Journal of Earthquake Engineering, 16(8):1132-1160.

Guo A, Cui L, Li S, Li H. (2015). A phenomenological contact-element model considering slight non-uniform contact for pounding analysis of highway bridges under seismic excitations. Earthquake Engineering \& Structural Dynamics, 44(11):1677-1695.

Hibbett, Karlsson, Sorensen. (1998). ABAQUS/standard: User's Manual (Vol. 1). Hibbitt, Karlsson \& Sorensen.

Hunt KH, Crossley FRE. (1975). Coefficient of restitution interpreted as damping in vibroimpact. Journal of Applied Mechanics, 42(2):440-445.

Jankowski R, Wilde K, Fujino Y. (1998). Pounding of superstructure segments in isolated elevated bridge during earthquakes. Earthquake Engineering \& Structural Dynamics, 27(5):487-502.

Jankowski R. (2005). Non-linear viscoelastic modeling of earthquake-induced structural pounding. Earthquake Engineering \& Structural Dynamics, 34(6):595-611.

Jankowski R. (2006a). Analytical expression between the impact damping ratio and the coefficient of restitution in the non-linear viscoelastic model of structural pounding. Earthquake Engineering \& Structural Dynamics, 35(4):517-524.

Jankowski R. (2006b). Pounding force response spectrum under earthquake excitation. Engineering Structures, 28(8):1149-1161.

Jankowski R. (2008a). Comparison of numerical models of impact force for simulation of earthquake-induced structural pounding. Computational Science-ICCS 2008 710-717.

Jankowski R. (2008b). Earthquake-induced pounding between equal height buildings with substantially different dynamic properties. Engineering Structures, 30(10):2818-2829.

Jankowski R. (2010). Experimental study on earthquake-induced pounding between structural elements made of different building materials. Earthquake Engineering \& Structural Dynamics, 39(3):343-354.

Jankowski R, Seleemah A, Elkhoriby S, Elwardany H. (2015). Experimental Study on Pounding between Structures during Damaging Earthquakes. Key Engineering Materials, 627:249-252.

Jeng V, Tzeng WL. (2000). Assessment of seismic pounding hazard for Taipei City. Engineering Structures, 22(5):459-471.

Kagermanov A, Ceresa P, Morales E, Poveda J, O’Connor J. (2017). Seismic performance of RC buildings during the MW7.8 Muisne (Ecuador) earthquake on April 2016: field observations and case study. Bulletin of Earthquake Engineering, DOI: 10.1007/s10518-017-0182-y.

Karayannis CG, Favvata MJ. (2005). Earthquake-induced interaction between adjacent reinforced concrete structures with non-equal heights. Earthquake Engineering \& Structural Dynamics, 34(1):1-20.

Kasai K, Maison BF. (1997). Building pounding damage during the 1989 Loma Prieta earthquake. Engineering Structures, 19(3):195-207.

Kharazian A, (2017). Analysis of seismic pounding of moderate height RC buildings with aligned slabs. Doctoral Dissertation, Technical University of Catalonia.

Kharazian A, López-Almansa F. (2017). Study on pounding effect between short-to-mid height RC buildings with aligned slabs. 16WCEE Santiago, Chile. 
Khatiwada S, Chouw N, Butterworth JW. (2011). Development of pounding model for adjacent structures in earthquakes. Ninth Pacific Conference on Earthquake Engineering, Auckland, NZ.

Khatiwada S, Chouw N, Butterworth JW. (2013a). Evaluation of numerical pounding models with experimental validation, Bulletin of the New Zealand Society for Earthquake Engineering, 46(3):117-130.

Khatiwada S, Chouw N, Larkin T. (2013b). An Experimental Study on Pounding Force between Reinforced Concrete Slabs. Australian Earthquake Engineering Society Conference, Hobart, Tasmania.

Khatiwada S, Chouw N, Larkin T. (2013c). Simulation of structural pounding with the sears impact model. $4^{\text {th }}$ ECCOMAS Thematic Conference on Computational Methods in Structural Dynamics and Earthquake Engineering, Kos Island, Greece.

Khatiwada S, Chouw N. (2014). Limitations in simulation of building pounding in earthquakes. International Journal of Protective Structures, 5(2):123-150.

Khatiwada S, Chouw N, Butterworth J. W. (2014). A generic structural pounding model using numerically exact displacement proportional damping. Engineering Structures, 62, 33-41.

Khatiwada S, Larkin T, Chouw N. (2014). Influence of mass and contact surface on pounding response of RC structures. Earthquakes and Structures, 7(3):385-400.

Khatiwada S, Chouw N, Larkin T. (2015). Discussion on "relaxation method for pounding action between adjacent buildings at expansion joint”. Earthquake Engineering \& Structural Dynamics, 44(1):159-162.

Komodromos P, Polycarpou PC, Papaloizou L, Phocas MC. (2007). Response of seismically isolated buildings considering poundings. Earthquake Engineering \& Structural Dynamics, 36(12):1605-1622.

Kun Y, Li L, Hongping Z. (2009a). A modified Kelvin impact model for pounding simulation of base-isolated building with adjacent structures. Earthquake Engineering and Engineering Vibration, 8(3):433-446.

Kun Y, Li L, Hongping Z. (2009b). A note on the Hertz contact model with nonlinear damping for pounding simulation. Earthquake Engineering \& Structural Dynamics, 38(9):1135-1142.

Li B, Bi K, Chouw N, Butterworth JW, Hao H. (2012). Experimental investigation of spatially varying effect of ground motions on bridge pounding. Earthquake Engineering \& Structural Dynamics, 41(14):1959-1976.

Liu Y, Liu WG, Wang X, He WF, Yang QR. (2014). New equivalent linear impact model for simulation of seismic isolated structure pounding against moat wall. Shock and Vibration, 2014(151237):1-10.

López-Almansa F, Kharazian A. (2014). Parametric study of the pounding effect between adjacent RC buildings with aligned slabs. 15ECEE Istanbul, Turkey.

Madani B, Behnamfar F, Tajmir Riahi H. (2015). Dynamic response of structures subjected to pounding and structure-soil-structure interaction. Soil Dynamics and Earthquake Engineering, 78:46-60.

Mahmoud S, Jankowski, R. (2011). Modified linear viscoelastic model of earthquake-induced structural pounding. Iranian Journal of Science and Technology, 35:51-62.

Mahmoud S, Abd-Elhamed A, Jankowski R. (2013). Earthquake-induced pounding between equal-height multistorey buildings considering soil-structure interaction. Bulletin of Earthquake Engineering, 11(4):1021-1048.

Maison BF, Kasai K. (1990). Analysis for a type of structural pounding. Journal of Structural Engineering, 116(4):957-977.

Maison BF, Kasai K. (1992). Dynamics of pounding when two buildings collide. Earthquake Engineering \& Structural Dynamics, 21(9):771-786.

Malhotra PK. (1998). Dynamics of seismic pounding at expansion joints of concrete bridges. Journal of Engineering Mechanics, 124(7):794-802.

Marin AV. (2014). Development and implementation of a biaxial contact element to analyze pounding in highway bridges with deck rotation under bidirectional seismic excitation. MsC Thesis, Technical University of Catalonia.

Masroor A, Mosqueda G. (2012). Experimental simulation of base-isolated buildings pounding against moat wall and effects on superstructure response. Earthquake Engineering \& Structural Dynamics. 41:2093-2109.

Mavronicola EA, Polycarpou PC, Komodromos P. (2015). The effect of modified linear viscoelastic impact models on the pounding response of a base isolated building with adjacent structures. $5^{\text {th }}$ International Conference on Computational Methods in Structural Dynamics and Earthquake Engineering, Crete, Greece.

Mavronicola EA, Polycarpou PC, Komodromos P. (2016). Effect of Planar Impact Modeling on the Pounding Response of Base-Isolated Buildings. Frontiers in Built Environment, 2:11.

Mavronicola EA, Polycarpou PC, Komodromos P. (2017). Spatial seismic modeling of base-isolated buildings pounding against moat walls: effects of ground motion directionality and mass eccentricity. Earthquake Engineering \& Structural Dynamics, 46:1161-1179.

Muthukumar S, Des Roches R. (2006). A Hertz contact model with non-linear damping for pounding simulation. Earthquake Engineering \& Structural Dynamics, 35(7):811-828.

Naderpour H, Khatami SM, Barros RC. (2017). Prediction of Critical Distance between Two MDOF Systems Subjected to Seismic Excitation in Terms of Artificial Neural Networks. Periodica Polytechnica Civil Engineering, 61(3):516-529. 
Naserkhaki S, Aziz FNAA, Pourmohammad H. (2012). Earthquake induced pounding between adjacent buildings considering soil-structure interaction. Earthquake Engineering and Engineering Vibration, 11(3):343-358.

Pant DR, Wijeyewickrema AC, Ohmachi T. (2010). Three-dimensional nonlinear analysis of seismic pounding between multi-story reinforced concrete buildings. 7CUEE 5ICEE, Tokyo.

Pant DR, Wijeyewickrema AC, Ohmachi T. (2010). Seismic Pounding between Reinforced Concrete Buildings: A Study using two recently proposed Contact Element Models. 14ECEE, Beijing.

Pant DR, Wijeyewickrema AC. (2012). Pounding of Seismically Isolated Reinforced Concrete Buildings Subjected to Near-Fault Ground Motions. 15WCEE, Lisbon.

Pantelides CP, Ma X. (1998). Linear and nonlinear pounding of structural systems. Computers \& Structures, 66(1):79-92.

Papadrakakis M, Mouzakis H. (1995). Earthquake simulator testing of pounding between adjacent buildings. Earthquake Engineering and Structural Dynamics, 24:811-834.

Papadrakakis M, Apostolopoulou C, Zacharopoulos A, Bitzarakis S. (1996). Three-dimensional simulation of structural pounding during earthquakes. Journal of Engineering Mechanics, 122(5):423-431.

PEER. (2015). Open System for Earthquake Engineering Simulation (OpenSEES). Pacific Earthquake Engineering Research Center, Berkeley.

Polycarpou PC, Komodromos P. (2010a). Earthquake-induced poundings of a seismically isolated building with adjacent structures. Engineering Structures, 32(7):1937-1951.

Polycarpou PC, Komodromos P. (2010b). On poundings of a seismically isolated building with adjacent structures during strong earthquakes. Earthquake Engineering and Structural Dynamics, 39(8):933-940.

Polycarpou PC, Komodromos P. (2011). Numerical investigation of potential mitigation measures for poundings of seismically isolated buildings. Earthquake and Structures, 2(1):1-24.

Polycarpou PC, Komodromos P, Polycarpou AC. (2013). A nonlinear impact model for simulating the use of rubber shock absorbers for mitigating the effects of structural pounding during earthquakes. Earthquake Engineering \& Structural Dynamics, 42(1):81-100.

Polycarpou PC, Papaloizou L, Komodromos P. (2014). An efficient methodology for simulating earthquakeinduced 3D pounding of buildings. Earthquake Engineering \& Structural Dynamics, 43(7):985-1003.

Polycarpou PC, Papaloizou L, Komodromos P, Charmpis DC. (2015). Effect of the seismic excitation angle on the dynamic response of adjacent buildings during pounding. Earthquakes and Structures, 8(5):1127-1146.

Rahman AM, Carr AJ, Moss PJ. (2001). Seismic pounding of a case of adjacent multiple-storey buildings of differing total heights considering soil flexibility effects. Bulletin of the New Zealand National Society for Earthquake Engineering, 34(1):40-59.

Rezavandi A, Moghadam AS. (2007). Experimental and numerical study on pounding effects and mitigation techniques for adjacent structures. Advances in Structural Engineering, 10(2):121-134.

Rosenblueth E. (1986). The 1985 earthquake: Causes and effects in Mexico City. Concrete International, 8:2334.

Ruangrassamee A, Kawashima K. (2001). Relative displacement response spectra with pounding effect. Earthquake Engineering \& Structural Dynamics, 30(10):1511-1538.

Ruangrassamee A, Kawashima K. (2003). Control of nonlinear bridge response with pounding effect by variable dampers. Engineering Structures, 25(5):593-606.

Sasaki T, Sato E, Fukuyama K, Kajiwara K. (2017). Enhancement of base-isolation based on E-defense fullscale shake table experiments: dynamic response of base-isolated building under impact due to pounding. 16WCEE.

Schmid G, Chouw N. (1992). Soil-structure interaction effects on structural pounding. 10WCEE, Madrid, Spain.

Sears J. (1912). On longitudinal impact of metal rods II. Transactions of the Cambridge Physical Society 21:49106.

SeismoSoft. (2016). A computer program for static and dynamic nonlinear analysis of framed structures. Available from SeismoSoft.com.

Stronge WJ. (2004). Impact mechanics. Cambridge University Press.

Shakya M, Kawan CK. (2016). Reconnaissance based damage survey of buildings in Kathmandu valley: An aftermath of $7.8 M_{\mathrm{w}}$, 25 April 2015 Gorkha (Nepal) earthquake. Engineering Failure Analysis, 59:161-184.

Takabatake H, Yasui M, Nakagawa Y, Kishida A. (2014). Relaxation method for pounding action between adjacent buildings at expansion joint. Earthquake Engineering \& Structural Dynamics, 43(9):1381-1400.

Takabatake H, Yasui M, Nakagawa Y, Kishida A. (2015). Response to short communication on Relaxation method for pounding action between adjacent buildings at expansion joint. Earthquake Engineering \& Structural Dynamics, 44(1):163-165.

Valles RE, Reinhorn AM. (1997). Evaluation, prevention and mitigation of pounding effects in building structures. 11WCEE, Acapulco, México. 
Van Mier, JGM, Pruijssers AF, Reinhardt HW, Monnier T. (1991). Load-time response of colliding concrete bodies. Journal of Structural Engineering, 117(2):354-374.

Watanabe G, Kawashima K. (2004). Numerical simulation of pounding of bridge decks. 13WCEE, Vancouver.

Weimin D. (2000). Chi-Chi, Taiwan Earthquake Event Report. Risk Management Solutions, 16. Retrieved from http://forms2.rms.com/rs/729-DJX-565/images/eq_chi_chi_taiwan_eq.pdf.

Wilson EL, Hollings JP, Dovey HH. (1979). Etabs: Three dimensional analysis of building systems. Earthquake Engineering Research Center, University of California.

Yaghmaei-Sabegh S, Jalali-Milani N. (2012). Pounding force response spectrum for near-field and far-field earthquakes. Scientia Iranica, 19(5):1236-1250.

Zhai C, Jiang S, Li S, Xie L. (2015). Dimensional analysis of earthquake-induced pounding between adjacent inelastic MDOF buildings. Earthquake Engineering and Engineering Vibration, 14(2):295-313.

Zhu P, Abe M, Fujino Y. (2002). Modelling three-dimensional non-linear seismic performance of elevated bridges with emphasis on pounding of girders. Earthquake Engineering \& Structural Dynamics, 31(11):1891-1913.

\section{LIST OF SYMBOLS}

$A$ : Cross-section area, integration constant (equations (3))

$B, C, D$ : Integration constants (equations (3))

$c$ : Traveling axial waves velocity $\left(c=\left(\frac{E}{\bar{\rho}}\right)^{1 / 2}\right)$, damping coefficient

$d$ : Gap between two adjoining colliding buildings

$E$ : Equivalent elastic deformation modulus

$E A_{1} / E A_{2}$ : Axial stiffness of the left/right colliding slabs

$F$ : Impact force

$k$ : Stiffness of Kelvin-Voigt model

$L$ : Length of the colliding slabs (in the pounding direction)

$m$ : mass of a building or frame

$m_{1} / m_{2}$ : Equivalent mass of the colliding of slabs of the left/right buildings

$N$ : Axial force (tension positive)

$q$ : Time-dependent factor in the eigenvalue analysis of axial vibrations

$r / r '$ : Restitution factor

$t$ : Time, impact duration

$\bar{m}_{0}$ : Part of external mass per unit length that is mobilized during the axial vibrations

$t$ : Time

$u$ : Axial displacement

$v_{1} / v_{2}$ : Traveling (absolute) velocities of left/right slabs in the beginning of the collision

$v_{\mathrm{c}}$ : Joint velocity, during impact, of the interface between both colliding bodies

$v_{1}$ : Traveling (absolute) velocity of the left slab at the end of the collision

$v_{2}{ }_{2} / v_{2}{ }_{2}$ : After-impact velocity of the right slab unstrained segment/After-impact average velocity of the right slab

$x / x_{1} / x_{2}$ : Coordinate/Coordinates of the colliding of slabs of the left/right buildings

$\delta$ : Axial displacement in the elastic impact analysis

$\varepsilon$ : Axial strain

$\phi$ : Modal shape in the eigenvalue analysis of axial vibrations

$\lambda$ : Wave length in the eigenvalue analysis of axial vibrations

$\omega$ : Angular frequency, natural frequency

$\rho / \bar{\rho}$ : Mass/equivalent mass per unit volume

$\zeta$ : Damping ratio

$\xi / \psi$ : Coordinates $(x-c t / x+c t)$ in the elastic impact analysis

$\zeta$ : Damping ratio 